\title{
TOPSIS Based Approach to Scoring Negotiating Offers in Negotiation Support Systems
}

\author{
Tomasz Wachowicz • Paweł Błaszczyk
}

Published online: 19 July 2012

C The Author(s) 2012. This article is published with open access at Springerlink.com

\begin{abstract}
In this paper we analyze the possibility of applying the technique for order preferences by similarity to ideal solution (TOPSIS) to building the scoring system for negotiating offers. TOPSIS is a multiple criteria decision making method that is based on measuring distances between alternatives under consideration and two bipolar reference alternatives, a positive and negative ideal. Thus the criteria used for the evaluation of alternatives should be described using strong scales. However, in the negotiation, the issues are very often described qualitatively, which results in ordinal or even nominal variables that must be taken into consideration in offers' evaluation process. What is more, TOPSIS may be applied to solving the discrete decision problems while the negotiation space may be defined by the means of continuous variables too. In this paper we try to modify the TOPSIS algorithm to make it applicable to negotiation support and, moreover, discuss the following methodological issues: using TOPSIS for a negotiation problem with continuous negotiation space; selecting the distance measure for adequate representation of negotiator's preferences and measuring distances for qualitative issues. Finally, we propose a simple additional mechanism that allows for building the TOPSIS-based scoring system for negotiating offers and does not involve negotiators in time consuming and tiresome preference elicitation process. This mechanism requires from negotiators to construct examples of offers that represent some categories of quality and then by using a goal programming approach it infers all the parameters required by the TOPSIS algorithm. We also
\end{abstract}

\footnotetext{
T. Wachowicz $(\varangle)$

Department of Operation Research, University of Economics in Katowice,

ul. 1 Maja 50, 40-287 Katowice, Poland

e-mail: tomasz.wachowicz@ue.katowice.pl

P. Błaszczyk

Institute of Mathematics, University of Silesia, ul. Bankowa 14, 40-007 Katowice, Poland

e-mail: pblaszcz@math.us.edu.pl
} 
show a simple prototype software tool that applies the TOPSIS modified algorithm and may be used in electronic negotiation support.

Keywords Negotiation support - Electronic negotiation - Preference analysis . Scoring system for negotiating offers - Continuous negotiation space - TOPSIS . Distance measures · Goal programming

\section{Introduction}

The last few decades have changed a perspective from which negotiations are perceived. On the one hand, lots of formal tools for negotiation support are being proposed since a new scientific discipline called the negotiation analysis has been developed (Raiffa 1982). These formal models and procedures are implemented as software solutions in a form of negotiation support systems. Some of these models have been implemented to support real world negotiation problems, such as RAINS (Hordijk 1991) used in resolving the dispute between the European countries negotiating air pollution limits, or the Deep Ocean Mining Model used in the United Nations UNCLOS III negotiations (Sebenius 1992) on the rights to exploit the natural resources from beneath of the sea bed and sharing the profits yielded from the exploitation. Recently, the basic supportive ideas derived from SmartSettle system (Thiessen and Soberg 2003) have been used for supporting First Nations Negotiation in Canada (Thiessen and Shakun 2009). On the other hand, the Internet expansion and e-commerce development cause that the vast majority of the business processes, including the negotiations, are conducted by means of computers and the Web, using both simple communication software such as electronic mail clients and instant messaging systems, and more sophisticated negotiation support systems or electronic negotiation systems. The last two usually support not only the communication process between parties but also accomplish some proactive functions such as individual decision support, negotiation protocol structuring, compromise searching, postoptimization analysis etc. (Kersten and Lai 2007). These systems are used for both solving real world problems and for training or teaching negotiations, such as FamillyWinner (Bellucci and Zeleznikow 2006), applied in a negotiation between divorcing couples in Australia and helping them to divide the family assets in the most fair way, Inspire (Kersten and Noronha 1999) used recently for an international research project on how negotiators behave in electronic negotiations (Paradis et al. 2010) or Negoisst (Schoop et al. 2003).

For accomplishing their decision support function NSSs need to apply formal models, which allow for analyzing negotiator's preferences, determining a scoring system for negotiating offers and then using this system for building negotiator's own proposals and analyzing his partner's counteroffers. Usually a simple additive weighting model, SAW (Keeney and Raiffa 1976) is used in negotiators' preference analysis (like in Inspire, Negoisst and SmartSettle systems), but the results of some research show, that the NSS's users very often misinterpret utilities scores used in SAW (Wachowicz and Kersten 2009). Other models are also applied into NSSs, based on different analytical approach, like the AHP (Mustajoki and Hamalainen 2000) or ELECTRE based ones (Wachowicz 2010). But all these solutions require negotiators to have at least the 
basic mathematical and decision making knowledge and the skills of abstract thinking, and very often involve them in a tiresome process of eliciting their preferences.

In this study we propose a new tool for analyzing negotiator's preferences and building the scoring system for negotiating offers that is based on the technique for order preferences by similarity to ideal solution (TOPSIS) (Hwang and Yoon 1981) and may be applied to negotiation support in a form of a simple software tool. Thanks to the application of some statistical methods into the process of preference analysis, the workload and time the negotiators have to devote for building their own scoring systems in the pre-negotiation phase are reduced. The original TOPSIS method operates on the set of predefined alternatives, i.e. it requires a decision (negotiation) problem to be formulated in a discrete form. However, in negotiations many issues are defined quantitatively (such as price, time of delivery etc.) and have a continuous character. It is easier to define them as the ranges of feasible values rather than the predefined salient options. Therefore, we propose our own modification of TOPSIS that makes it applicable to a negotiation problem containing continuous issues. Furthermore, TOPSIS assumes that the criteria under consideration are expressed on the strong scales, such as the ratio or interval ones. However, in negotiations some issues may be also described qualitatively or verbally, which results in the ordinal or even nominal variables, that must be taken into consideration in the evaluation process of offers. To solve this problem we propose a simple solution derived from Kaufman and Rousseeuw (1990) research work. Furthermore, we discuss the problem of using various distance measures and metrics in the TOPSIS scoring algorithm to determine the one-dimensional (single-issue) distance that reflects negotiator's preferences in the best possible way. Then we propose a goal-programming based approach that allows negotiators to build their scoring systems with an adequate form of the scoring (distance) function without specifying the parameters of this function explicitly. The negotiators are only asked to define some examples of the offers and assign the final score to each of them. Deriving from these assignments the algorithm decomposes the global score to single criteria scores and tries to find the forms of single-criterion distance functions that fit these scores the best. In the final step of the algorithm, the single criteria distance functions are used to build the TOPSIS global scoring formula. Having the TOPSIS based approach defined, we discuss shortly the possibilities of using it for a symmetric analysis in negotiations, mainly for finding improvements in a negotiation agreement. Finally, we propose a simple web-based negotiation support tool called TOBANS for facilitating the process of preference analysis and evaluation of negotiation offers.

\section{TOPSIS in Negotiation Support}

\subsection{TOPSIS Fundamentals}

TOPSIS was developed by Hwang and Yoon (1981) as a method for supporting multiple-criteria decision making. ${ }^{1}$ In general, TOPSIS allows to order all alterna-

\footnotetext{
1 There is an early paper by Hellwig (1968) that proposes very similar method for ordering alternatives using the same idea of measuring distances to ideal and anti-ideal alternatives which differs only in the
} 
tives under consideration by using a bipolar reference space. From the statistical point of view, for each alternative under consideration the distances to the positive and negative ideal solutions are calculated and then the global decision criterion is constructed, which is an aggregate of these two measures. For its simplicity TOPSIS has been applied to solve many real world decision problems in the field of logistics (Chamodrakas et al. 2009), building and construction (Zavadskas et al. 2010), ecology (Krohling and Campanharo 2011) or for analyzing human behavior (Milani et al. 2008). There are also lots of theoretical works on TOPSIS extensions showing how the method may be modified to solve problems of a particular formal structure with additional assumptions (Jahanshahloo et al. 2006; Shih et al. 2007). The simple introductory analysis of adaptability of TOPSIS for a scoring negotiation template has also been done earlier by Wachowicz (2011).

The TOPSIS requires a decision problem to be well structured and represented in a form of decision matrix $A$ with $m$ rows, each representing the alternative under consideration and $n$ columns, each representing the evaluation criterion. The matrix consists of $x_{j k}$ variables, each describing the resolution level (performance) of alternative $A_{j}(j=1, \ldots, m)$ with respect to the criterion $C_{k}(k=1, \ldots, n)$. Furthermore, the decision maker defines the vector of weights $w=\left(w_{1}, w_{2}, \ldots, w_{n}\right)$, where $\sum_{k=1}^{n} w_{k}=1$, reflecting the relative importance of the criteria. It is assumed, that the problem of vector maximization is considered, i.e. the decision maker prefers higher values to the lower ones for each decision criterion. However, the whole TOPSIS procedure may be applied to other types of decision problems with the slight changes in the algorithm only. The standard TOPSIS formal ordering procedure consists of the six following steps:

1. Building the normalized decision matrix:

$$
N=\left[\begin{array}{llll}
\hat{x}_{11} & \hat{x}_{12} & \cdots & \hat{x}_{1 n} \\
\hat{x}_{21} & \hat{x}_{22} & \cdots & \widehat{x}_{2 n} \\
\cdots & \cdots & \cdots & \cdots \\
\hat{x}_{m 1} & \hat{x}_{m 2} & \cdots & \widehat{x}_{m n}
\end{array}\right],
$$

where $\widehat{x}_{j k}$ is usually determined by using the following formula ${ }^{2}$

$$
\widehat{x}_{j k}=\frac{x_{j k}}{\sqrt{\sum_{j=1}^{m} x_{j k}^{2}}} .
$$

for $j=1, \ldots, m$ and $k=1, \ldots, n$.

\section{Footnote 1 continued}

construction of the final aggregate criterion. However, this work was published in the Polish language only and it is not widely known.

2 There are also other normalization procedures proposed for TOPSIS (see Milani et al. 2005). 
2. Computing the weighted normalized decision matrix:

$$
V=\left[\begin{array}{llll}
w_{1} \hat{x}_{11} & w_{2} \widehat{x}_{12} & \cdots & w_{n} \widehat{x}_{1 n} \\
w_{1} \widehat{x}_{21} & w_{2} \hat{x}_{22} & \cdots & w_{n} \widehat{x}_{2 n} \\
\cdots & \cdots & \cdots & \cdots \\
w_{1} \widehat{x}_{m 1} & w_{2} \widehat{x}_{m 2} & \cdots & w_{n} \widehat{x}_{m n}
\end{array}\right]=\left[\begin{array}{llll}
v_{11} & v_{12} & \cdots & v_{1 n} \\
v_{21} & v_{22} & \cdots & v_{2 n} \\
\cdots & \cdots & \cdots & \cdots \\
v_{m 1} & v_{m 2} & \cdots & v_{m n}
\end{array}\right]
$$

3. Determining the positive ideal $\left(A^{+}\right)$and negative ideal $\left(A^{-}\right)$solutions:

$$
A^{+}=\left(v_{1}^{+}, v_{2}^{+}, \ldots, v_{n}^{+}\right)
$$

where $v_{k}^{+}=\max _{j}\left(v_{j k}\right)$, for $k=1, \ldots, n$.

$$
A^{-}=\left(v_{1}^{-}, v_{2}^{-}, \ldots, v_{n}^{-}\right)
$$

where $v_{k}^{-}=\min _{j}\left(v_{j k}\right)$, for $k=1, \ldots, n .^{3}$

4. Calculating the separation measures (distance) from PIS $\left(d_{j}^{+}\right)$and NIS $\left(d_{j}^{-}\right)$for each alternative respectively:

$$
\begin{aligned}
& d_{j}^{+}=\sqrt[p]{\sum_{k=1}^{n}\left|v_{j k}-v_{k}^{+}\right|^{p}}, \quad \text { for } j=1, \ldots, m, \\
& d_{j}^{-}=\sqrt[p]{\sum_{k=1}^{n}\left|v_{j k}-v_{k}^{-}\right|^{p}}, \quad \text { for } j=1, \ldots, m,
\end{aligned}
$$

where $p$ is the distance coefficient.

Usually the Euclidean distance is used in the TOPSIS analysis, for which $\mathrm{p}=$ 2. However, other metrics and distance measures are also proposed (Jones and Mardle 2004).

5. Determining the relative closeness of each alternative to the ideal solution (the aggregated decision criterion):

$$
S_{j}=\frac{d_{j}^{-}}{d_{j}^{+}+d_{j}^{-}}, \quad \text { for } j=1, \ldots, m \text {, }
$$

where $0 \leq S_{j} \leq 1$. The closer the alternative $A_{j}$ to PIS is, the larger the value of $S_{j}$.

6. Ranking the alternatives in descending order using $S_{j}$.

\footnotetext{
3 For problems different from vector maximization ones formulas (4) and (5) may be also written in other forms (see Jahanshahloo et al. 2006).
} 
Having completed step number 6 of the TOPSIS procedure, the decision maker obtains a full order of the alternatives under consideration. The alternatives that are at the top of the ranking - at the beginning of the order (with the relative closeness score close to 1) - are perceived to be more preferred than the ones from the tail (with the score close to 0 ).

\subsection{Problems with Using TOPSIS for Decision Support in Negotiations}

TOPSIS may be used in negotiation support for building the scoring system for negotiating offers, which is used both in the prenegotiation preparation and later in the actual negotiation phase for evaluating the incoming offers (proposed by counterparts) or negotiator's own proposals (see Wachowicz 2011). The relative closeness $S_{j}$, being an aggregate criterion, may be perceived as a final score of the alternative, similarly to the scores obtained by means of simple additive weighting (see Keeney and Raiffa 1976) - the higher the score, the better the alternative is. Having the offers scored according to the TOPSIS procedure the negotiator knows then how good a particular offer proposed by his counterpart is and to what extend it is worse/better than the one proposed by the negotiator beforehand. He also knows how distant this offer is from his ideal solution (or how close it is to the worst possible offer defined by his reservation levels).

However, some problems may occur when applying a classic TOPSIS method for building the scoring system for negotiating offers. These problems are the results of high structuralization and formalization of the decision problem that is required for applying a standard TOPSIS algorithm. Four of these problems require a thorough consideration:

Problem 1 Predefining the decision matrix

Before executing the TOPSIS algorithm the decision problem needs to be formulated in a form of a decision matrix. To build such a matrix, a set of criteria (issues) and a full list of alternatives (feasible negotiation offers) have to be identified. Naturally, the consequences of all these alternatives for each single issue also need to be specified in terms of the cardinal numbers. It means, that TOPSIS requires a discrete decision problem definition, which could be troublesome since some negotiation issues may have a continuous character (such quantitative issues as: price, delivery time, royalties etc.). Once the quantitative issues may be continuous, this fact makes the set of feasible negotiation offers uncountable, and the scoring of them seems to be impracticable when using the original TOPSIS algorithm. The simplest solution to handle this problem could be introducing the set of salient options that represent the feasible range of values for each continuous issue (see Kersten and Noronha 1999). However, it limits the number of possible alternative solutions and consequently makes negotiators less flexible in creating the negotiation offers and counteroffers.

Problem 2 Using the same distance functions in symmetric analysis.

The standard TOPSIS algorithm applies the Minkowski distance for measuring distances between the alternatives. If a negotiation supportive mechanism is based on this 
standard algorithm, the same distance measure is applied for scoring the offers of both negotiators. In addition, if negotiators agreed for a common negotiation template, the same decision matrix is used as a basis for the scoring system. In such a situation the value (score) of each single-criterion concession is the same for both negotiators. As much as one negotiator gains in terms of score, the other will loose.

Let us compare two options of the issue "time of payment": 7 and 6 days after the delivery. The template allows the options to vary from 0 days (upon delivery) to 10 days. To normalize the option values, we apply a position normalization with the basis of $\max _{j} x_{j}$ (for the issue $j$ each option is divided by the maximum option value for $j$ ). We will analyze what is the contribution of these options to values of the separation measures (6) and (7) for both negotiators, each of them having the opposite preferences (a buyer prefers the longest time, a seller - the shortest time of payment). For the option "7 days" we obtain:

- the contribution to the buyer's $d_{j}^{+}$is equal to $|0.7-1|^{p}=0.3^{p}$, and to the buyer's $d_{j}^{-}$is equal to $|0.7-0|^{p}=0.7^{p}$,

- the contribution to the seller's $d_{j}^{+}$is equal to $|0.7-0|^{p}=0.7^{p}$, and to the seller's $d_{j}^{-}$is equal to $|0.7-1|^{p}=0.3^{p}$.

For the option "6 days" we obtain:

- the contribution to the buyer's $d_{j}^{+}$is equal to $|0.6-1|^{p}=0.4^{p}$, and to the buyer's $d_{j}^{-}$is equal to $|0.6-0|^{p}=0.6^{p}$,

- the contribution to the seller's $d_{j}^{+}$is equal to $|0.6-0|^{p}=0.6^{p}$, and to the seller's $d_{j}^{-}$is equal to $|0.6-1|^{p}=0.4^{p}$.

If the buyer makes a concession and moves form "7 days" to " 6 days", his $d_{j}^{+}$will increase by $\left|0.3^{p}-0.4^{p}\right|$ and $d_{j}^{-}$will decrease by $\left|0.7^{p}-0.6^{p}\right|$. For the seller the situation is quite the opposite. His $d_{j}^{+}$will decrease by $\left|0.7^{p}-0.6^{p}\right|$ while $d_{j}^{-}$will increase by $\left|0.3^{p}-0.4^{p}\right|$. Hence the increments and decrements of the scores are mutually known for each possible concession made on this issue. Consequently, the single-criterion structures of preferences become transparent. Such a structure of preferences is, however, the negotiators' strategic information that should not be disclosed to the counterpart. Revealing it will not allow for negotiating strategically, e.g. for using such a tactic as a bluff. Thus, some mechanisms need to be introduced to avoid the situation of preference transparency and allow negotiators to select the individual way of scoring negotiation options.

The problem becomes more serious if both parties assign the same weights to the negotiation issues, which may not be highly probable, but still possible. In such a case the scale of each concession made on a full package (a complete offer) is identical for both parties. It is because the scoring systems for negotiators are exactly opposite and a negotiation problem becomes in fact a zero-sum two-person game leaving no space for joint gains (see Sect. 5 for an example of such a situation).

Problem 3 Scoring the qualitative issues

TOPSIS requires the alternatives to be described numerically. What is more, the strong-scale numbers must be used, i.e. the interval or ratio level data is required. 
Yet, some negotiation issues may have a qualitative character and be expressed on weak scales (i.e. the ordinal or nominal ones). For instance the warranty issue may be described verbally in a form of a warranty policy. Even if the negotiator is able to build a preorder of different warranty policies, i.e. to rank them form the best to the worst one, we still need to operate with the ordinal scale numbers. From the statistical point of view, measuring distances between the different objects described by ordinal numbers is impossible, since the differences between these numbers are meaningless. Thus the question arises, what to do with the negotiation issues that use the weak-scale numbers or cluster the options into the categories that are imprecisely defined by the verbal descriptions or labels?

Problem 4 Representing the negotiator's preferences by the predefined distance functions

The only preference information the negotiators specify for the TOPSIS algorithm are the criteria weights. The algorithm does not require of the user to define singlecriterion preferences for all feasible resolution levels of each issue (what has already been mentioned in a different context while discussing the Problem 2). Instead of eliciting these preferences (e.g. in the interaction with the decision maker) TOPSIS uses an arbitrarily selected metric or distance measure for calculating the separation measures. But this particular metric or distance measure may not necessarily reflect true preferences (the preference function in particular) the negotiator has for different options of the issue under consideration. For instance, by using the Manhattan distance metric we assume that single-criterion preferences are linear, which does not need to be true. The analysis of the data obtained within a GRIN project (Paradis et al. 2010) shows, that the vast majority of negotiators define their preferences over the options nonlinearly. Therefore, the negotiation support mechanism should allow for selecting a distance function (to be applied in step 4 of the TOPSIS algorithm) the shape of which fits best the shape of negotiator's preference function (yet not explicitly defined).

Having defined the above problems, a new question arises: is it possible to modify or adjust somehow the classic TOPSIS algorithm, which would allow using it effectively for negotiation support, in particular for building the scoring system for negotiating offers? We will try to discuss this problem in the next section.

\section{TOPSIS Modifications}

Deriving from the preliminary analysis presented in the research paper by Wachowicz (2011), we will describe a few possible solutions to the problems mentioned in Sect. 2.2. We will consecutively discuss the problems of: using TOPSIS for problems with continuous negotiation spaces, using different distance measures to represent the negotiator's preference functions in the more accurate way and analyzing qualitative issues.

\subsection{Using TOPSIS for Negotiation Problems with Continuous Negotiation Space}

Firstly, we will focus on the TOPSIS methodological limitations that require the decision (negotiation) problem to be formulated in a discrete form. In the negotiation 
context it results in a strong structuring of the negotiation template, i.e. in predefining all the negotiation issues and all feasible resolution levels within the prenegotiation phase. Later on, in the actual negotiation phase, the only offers that may be negotiated (proposed by the parties) are the ones that consist of the options predefined in the prenegotiation phase. It makes the negotiation process inflexible and restricted to a relatively small number of potential solutions, whilst the satisfying agreement may require, for instance, using some intermediate but unavailable option values, i.e. the offers randomization. Therefore, we will modify the TOPSIS approach to be applicable for scoring offers in the problem that consists of continuous issues, what we call a continuous negotiation space or continuous negotiation problem. We will assume however, that the minimum structuration of the negotiation process is possible, i.e. all the negotiation issues can be predefined in advance.

The TOPSIS algorithm operates on a decision matrix $A$, using elements of this matrix to build a normalized decision matrix $N$ (step no. 1) and to identify the PIS and NIS alternatives (step no. 3). To find PIS and NIS the maximum and minimum values are identified within each column of this matrix. Moreover, in the normalization formula (2) the sum of squares of the matrix elements is used as the basis for normalization (see the formula's denominator). However, another approach may be applied, which does not refer to all matrix elements. When defining PIS and NIS alternatives we may ask the negotiator to define his aspiration and reservation levels in a form of complete packages ( $A_{a s p}$ and $A_{\text {res }}$ respectively) comprised of the option values, which will be used to define the negotiation space for each criterion (the range of feasible values). Then, instead of the formula (2), another normalization formula may be used, like the one that refers to the interval between the extreme values. For instance, the following linear normalization formula may be applied

$$
\widehat{x}_{j k}=\frac{x_{j k}-x_{k}^{r e s}}{x_{k}^{a s p}-x_{k}^{r e s}}, \quad \text { for } k=1, \ldots, n
$$

where $x_{k}^{\text {asp }}$ denotes the maximum feasible value of $k$ th issue, defined by the aspiration package $A_{a s p}, x_{k}^{r e s}$ denotes the minimum feasible value of $k$ th issue, defined by the reservation package $A_{r e s}, x_{j k}$ denotes the value of $k$ th issue in any offer $j$ that dominates $A_{\text {res }}$ and is dominated by $A_{a s p}{ }^{4}$ (any feasible offer).

To obtain PIS and NIS alternatives that are required for further calculations we need to normalize the aspiration and reservation packages. Please note that according to the formula (9) PIS and NIS alternatives will become the vectors of the following forms

$$
\begin{aligned}
& A^{+}=\left[\widehat{x}_{k}: \underset{k=1, \ldots, n}{\forall} \widehat{x}_{k}=1\right], \\
& A^{-}=\left[\widehat{x}_{k}: \underset{k=1, \ldots, n}{\forall} \widehat{x}_{k}=0\right] .
\end{aligned}
$$

\footnotetext{
4 The vector domination is considered.
} 
Since we consider the continuous negotiation problem, we do not have explicitly defined the weighted normalized matrix $V$, either. However, the issue weights still need to be taken into consideration in the evaluation of offers. Therefore, the separation measures, given originally by the formulas (6) and (7), must be modified. We propose to use the classic Gower's measure ${ }^{5}$ (Gower 1971), denoted by $d_{a b}^{G}$, which is an aggregate of the weighted single-criterion distances between two alternatives $a$ and $b$

$$
d_{a b}^{G}=\frac{\sum_{k=1}^{n} w_{k} d_{a b, k}}{\sum_{k=1}^{n} w_{k}},
$$

where $d_{a b, k}$ denotes the distance between two alternatives $a$ and $b$ for $k$ th criterion.

We have assumed before that the sum of criteria weights is equal to 1 , therefore, the denominator in the formula (12) is always equal to 1 and the whole formula may be simplified

$$
d_{a b}^{G}=\sum_{k=1}^{n} w_{k} d_{a b, k}
$$

We will assume that the distance $d_{a b}^{G}$ is calculated using the option values of the alternatives $a$ and $b$ that are normalized according to the formula (9). Having defined the Gower's distance measure, we may use it for calculating separation measures $d_{j}^{+}=d_{j A_{\text {asp }}}^{G}$ and $d_{j}^{-}=d_{j A_{\text {res }}}^{G}$ for any feasible negotiation offer $j$. The relative closeness $\left(S_{j}\right)$ of $j$ th alternative to the ideal solution $\left(A_{a s p}\right)$ may be determined then using the original formula (8).

Summarizing the TOPSIS modifications discussed in this subsection, the preparation of the scoring system used by the negotiator for evaluating the offers in continuous negotiation problem will consists of the six following steps:

1. Defining the negotiation problem by identifying $n$ possible negotiation issues.

2. Defining the aspiration and reservation packages $\left(A_{a s p}\right.$ and $\left.A_{\text {res }}\right)$ that specify the most wanted and the worst acceptable options for all $n$ issues under consideration.

3. Defining the importance of issue in a form of the vector of weights $w=$ $\left(w_{1}, w_{2}, \ldots, w_{n}\right)$, where $\sum_{k=1}^{n} w_{k}=1$.

4. Initiating the normalization formula (9) with $x_{k}^{\text {asp }}$ and $x_{k}^{\text {res }}$ values derived from $A_{\text {asp }}$ and $A_{\text {res }}$.

5. Initiating the distance measure formula (12) with the $w_{k}$ values derived form the vector of weights $w$.

6. Building a scoring formula by applying the relative closeness formula (8) and using the distance measure and normalization formulas initiated in steps 4 and 5 .

Having prepared the scoring formula, as described in step no. 6 of the above procedure, we may evaluate any offer selected from the feasible negotiation space.

\footnotetext{
5 The remarkable advantage of Gower's measure is that it may be also used for measuring distances between alternatives when the respective issues are expressed on different scales.
} 
3.2 Selection of the Distance Measure for Adequate Representation of Negotiator's Preferences

Before utilizing the new TOPSIS based procedure described in Sect. 3.1 the problem of using an adequate distance measure (or metric) for determining the $d_{a b, k}$ values in the Gower's formula (12) needs to be discussed first. It is very important methodological issue, since the TOPSIS distance formula reflects the negotiator's preferences and, therefore, an adequate measure should be selected that corresponds to the negotiator's true preference function the most. Usually, the Minkowski formula [see (6) and (7)] is proposed. Taking into account the single-criterion aspect of Minkowski formula, which comes down to calculating the absolute value of the difference between the comparing option values

$$
d_{a b, k}=\left|\hat{x}_{a k}-\hat{x}_{b k}\right|
$$

the distance value linearly increases as we move form the best option $x_{k}^{a s p}$ to the worst one $x_{k}^{r e s}$. Thus, the application of Minkowski formula imposes the linear form of preference function for the supported negotiator, whereas negotiators may have nonlinear preferences over the option values of each issue. There are, however, other distance measures that may be used for modeling non-linear preferences.

Three popular measures: the Canberra metric, Lance-Williams coefficient and Clark distance result in non-linear distance function and have the same formula if a singlecriterion distance is considered

$$
d_{a b, k}^{=} \frac{\left|\hat{x}_{a k}-\hat{x}_{b k}\right|}{\hat{x}_{a k}+\hat{x}_{b k}} .
$$

These three measures are sensitive to small changes of values $\hat{x}_{a k}$ and $\hat{x}_{b k}$, close to 0 (see Gordon 1999). In her recent study Pawełek (2008) shows that from the methodological point of view the sensitivity level of these measures may be modeled by extracting the $q$ th root from the formula (15). The higher value $q$, the more sensitive for small changes of values close to 0 the measure is. For $q<1$ the measure becomes more sensitive to small changes close to the maximum feasible value (here $x_{k}^{a s p}$ ). This operation makes the distance function more similar to various shapes of preference functions, in particular to different types of DARA and INARA utility functions.

In our approach we will use Pawełek's idea to model the distance function consistent with the negotiator's true preference function. We will apply, however, the Minkowski single-criterion distance [formula (14)], the interpretation of which is more intuitive and which allows for mapping linear preferences for $q=1$ if necessary. Therefore, the final formula that we will use for measuring the distance between two alternatives $a$ and $b$ for $k$ th criterion has the following form

$$
d_{a b, k}=\sqrt[q]{\left|\hat{x}_{a k}-\hat{x}_{b k}\right|} .
$$

In Fig. 1 various single-criterion distance functions for different $q$ coefficients are presented, showing the distances between $x_{k}^{a s p}=1$ and $\hat{x}_{b k} \in\langle 0 ; 1\rangle$. 


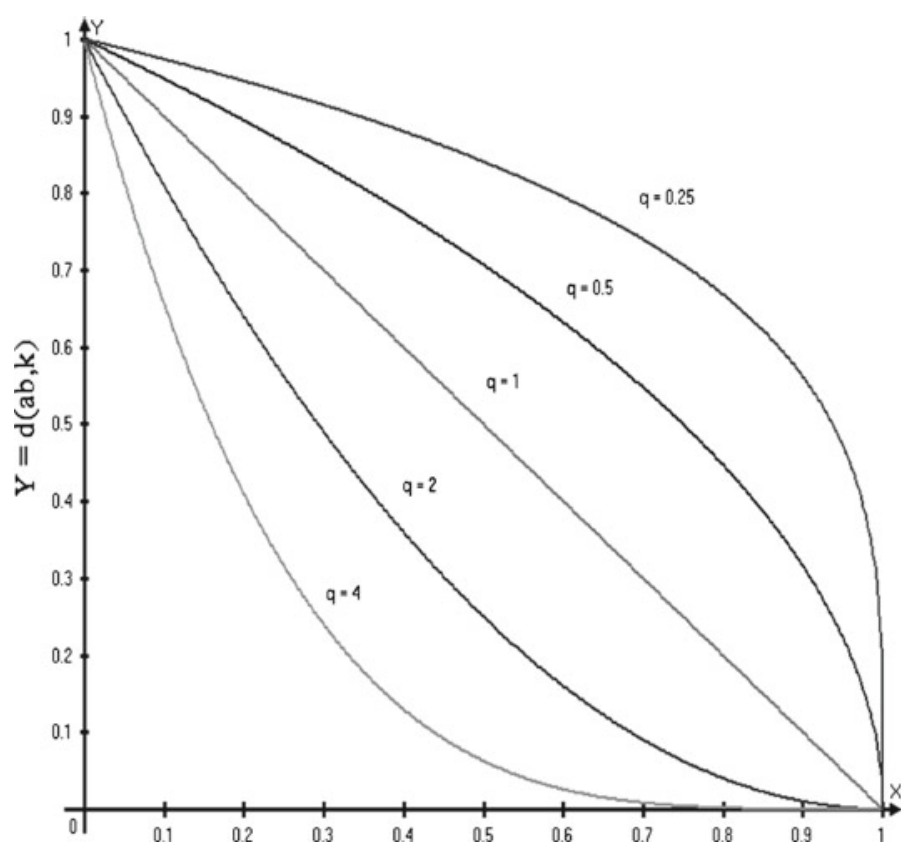

Fig. 1 Single-criterion rooted Minkowski distance (16) for various root coefficients $q$

The adequate root coefficients $q$ required by the single-criterion distance function (16) need to be somehow assigned to the supported negotiator to reflect correctly his preferences. The simplest way to determine the $q$ value is to present the different shapes of distance function to the negotiator who selects then the form representing his preferences in the best possible way. To make his decision easier the distance function (16) may be transformed into the similarity function using the standard statistic transformation between the similarity and dissimilarity measures (see Gordon 1999; Cox and Cox 2001):

$$
S_{x_{k}^{a s p} a, k}=\widehat{x}_{k}^{a s p}-d_{x_{k}^{a s p} a, k}=1-d_{x_{k}^{a s p} a, k} .
$$

The similarity index $s_{x_{k}^{a s p} a, k}$ may be interpreted as the quality of the option $a$ of the $k$ th issue. Conceptually, the similarity function may be compared with the preference function that a negotiator builds by assigning the scores (e.g. utilities) in simple additive weighting method.

Having the $q$ coefficient determined, and consequently knowing the types of the similarity/distance functions, we may enter them to the scoring formula that is built in step no. 6 of the modified TOPSIS algorithm (see Sect. 3.1). According to the Gower's distance measure (13), to determine the multi-criteria distance between the alternatives the single-criterion distances (16) need to be aggregated with criteria weights. 


\subsection{Measuring Distances for Qualitative Issues}

Some negotiation issues may have a typically descriptive character or be a complex of a few factors. The returns or warranty policy issues in business negotiation or insurance option in employee-employer negotiation are the examples of such decision criteria. They cannot be divided into sub-issues since they may be dependent in the sense of preferences, i.e. for the seller the evaluation of the amount of penalty may depend on the level of spoilage accepted by the buyer. If the negotiator knows or is able to intuitively establish the preorder of such options, we face the problem of ordinal-scale issue. If not, we need to operate on the nominal scale.

The problem of measuring distances between the options of weak-scale negotiation issues is of the methodological nature and involves the philosophical aspects of decision making. It was discussed earlier in detail in the paper by Wachowicz (2011). Here we simply apply one of the commonly known and accepted solutions proposed by Kaufman and Rousseeuw (1990), who gave a rationale to use it for ordinal data variables. We will assume then that for each qualitative issue the options are ranked by the negotiator, so the order of the option is known (the highest rank, the better the option is). It will allow us to determine a single-criterion distance between two options $a$ and $b$ of issue $k$ using the following formula

$$
d_{a b, k}=\frac{\left|x_{a k}-x_{b k}\right|}{x_{k}^{\max }-x_{k}^{\min }},
$$

where $x_{a k}, x_{b k}$ are the ranks of options $a$ and $b$ (of issue $k$ ), and $x_{k}^{\max }, x_{k}^{\min }$ are the maximum and minimum ranks that were used in ordering the options of issue $k$.

The result is in fact the same as if we used the standard Minkowski formula (14) for normalized data, which is obligatory in the TOPSIS approach. Some authors criticize the Kaufman and Rousseeuw proposition, arguing that the addition and subtraction are the properties of the interval and ratio scales only. Therefore, when using the formula (18) the negotiator needs to be aware, that the equal distance between the subsequent ordinal categories is assumed, i.e. the difference in a quality when moving from category 1 to 2 is the same when moving from 3 to 4 .

\section{Deriving the Form of TOPSIS Distance Function From the Offers Examples}

In Sect. 3.2 we have proposed to root the distance function used by the TOPSIS algorithm, which allows for adjusting the form of this function to the negotiator's preference function the most. The only problem with the proposed approach is to find an adequate $q$ coefficient, which is an artificial factor of no intuitive interpretation and, therefore, may not be explicitly and correctly given by the negotiator himself. Thus we propose to derive the $q_{k}$ root coefficients for each single criteria function $(k=1, \ldots$, $n$ ) using the examples of offers the negotiator may specify and evaluate as complete packages in the prenegotiation phase. We may find the $q_{k}$ coefficients by applying a mathematical programming approach. 


\subsection{The Model}

To build the mathematical programming model we need to assume that the negotiator has already completed all prenegotiation tasks, in particular, that he has built the negotiation template and identified some possible alternatives for negotiation agreement (see Zartman 1989; Raiffa et al. 2002; Simons and Tripp 2003). Thus he knows what are the various, more or less attractive, alternative solutions to the negotiation problem. If so, he can construct a set of exemplary negotiation offers $O$, and assign to the each package defined in $O$ the numerical scores that reflect his preferences. If he finds operating with numerical scores difficult, the verbal scales may be used (see Larichev and Moshkovich 1997; Chen 2000). The linguistic evaluations made by the negotiator are then mapped into the numerical equivalents. To be coherent with the TOPSIS classic algorithm the score should have a value from the range $[0 ; 1]$, where value 1 is assigned to the best possible (most preferred) offer, while value 0 - to the worst one. If not, the values specified by the negotiator may always be normalized to fulfil the above condition.

Having the offers and their evaluations (the assignments) specified, we build the goal programming model, in which the goal constrains are the relative closeness formulas (8), constructed for each alternative from the set $O$ respectively, and the right hand sides of which are supplemented with the unwanted deviation coefficients. The additional constraints may also be taken into consideration that would allow for limiting the range of possible $q_{k}$ values. Too high or too low $q_{k}$ values result in extremely convex or concave forms of distances functions that are less sensitive to changes of the option values negotiators want to score (see Sect. 3.2).

Formally, we denote by

$$
O=\left[\begin{array}{llll}
o_{11} & o_{12} & \cdots & o_{1 n} \\
o_{21} & o_{22} & \cdots & o_{2 n} \\
\cdots & \cdots & \cdots & \cdots \\
o_{I 1} & o_{I 2} & \cdots & o_{I n}
\end{array}\right]
$$

the set of $I$ negotiation offers constructed by the negotiator, and by

$$
S^{O}=\left[S_{1}^{O}, S_{2}^{O}, \ldots, S_{I}^{O}\right]
$$

the vector of scores the negotiator assigns to each of the offers predefined within the set $O$. Having the vector of weights $w$ required by the classic TOPSIS algorithm (see Sect. 2) and the definition of the aspiration and reservation levels $A_{a s p}$ and $A_{\text {res }}$ required by the TOPSIS modifications (see Sect. 3.1) we may build the goal programming problem in the following form:

$$
\min \sum_{i=1}^{I} Y_{i}^{+}+\sum_{i=1}^{I} Y_{i}^{-}
$$


subject to

$$
\begin{aligned}
& \frac{\hat{d}_{i}^{-}}{\hat{d}_{i}^{-}+\hat{d}_{i}^{+}}-Y_{i}^{+}+Y_{i}^{-}=S_{i}^{O}, \quad \text { for } i=1, \ldots, I, \\
& q_{k} \geq 0, \quad \text { for } k=1, \ldots, n, \\
& Y_{i}^{+}, Y_{i}^{-} \geq 0, \quad \text { for } i=1, \ldots, I,
\end{aligned}
$$

where

$$
\begin{aligned}
& \hat{d}_{i}^{+}=\sum_{k=1}^{n} w_{k} \sqrt[q_{k}]{|| 1-\frac{o_{i k}-x_{k}^{r e s}}{x_{k}^{a s p}-x_{k}^{r e s}} \mid}, \\
& \hat{d}_{i}^{-}=\sum_{k=1}^{n} w_{k} \sqrt[q_{k}]{\left|0-\frac{o_{i k}-x_{k}^{r e s}}{x_{k}^{a s p}-x_{k}^{r e s}}\right|} .
\end{aligned}
$$

By solving the goal programming problem defined above we obtain the values of $q_{k}$ coefficients that may be used to initiate the distance measure formulas (12) within the step 5 of the proposed algorithm (see Sect. 3.1). Having the distance measure defined, we build the scoring system for negotiating offers (step 6 of the algorithm) that permits us to score any negotiation offer from between $A_{a s p}$ and $A_{\text {res }}$ according to negotiator's preferences defined by means of the offers examples $O$.

From the technical point of view any non-linear optimization package could be used for solving the model described above. However, before applying it into negotiation support the minimal number of offer examples, that comprise the set $O$, needs to be decided. The model, that is to be built, has to contain enough information so as to infer adequately all $q_{k}$ coefficients. Yet, from the methodological point of view, there are no strict requirements of the minimum or maximum number of the alternatives to be defined. It is possible to define the model containing one constraint only $(n=1)$, but it would not be sufficient to find the true forms of distance functions. We would find probably the alternative solutions for such a defined problem, so the different combinations of $q_{k}$ would allow for minimizing the objective function (21). On the other hand, too many assignments may involve the inconsistencies in the negotiators preference definition. That would lead to increase in the value of the objective function and determining the less precise TOPSIS distance function coefficients $q_{k}$. The only recommendation that may be given is that the profiles of the alternatives defined within the assignments should be "as different as possible", showing how the various trade-offs influence the global scores of the alternatives. They should also be the examples of the offers of different quality. For instance, if the verbal evaluation is used, the examples of various categories of quality should be given, i.e. some good, medium and poor offers should be specified. They are anyway the recommendations that are usually given for other similar problems of inferring the model parameters by means of mathematical programming approach (see Mousseau 1995; Mousseau and Slowinski 1998). 
Table 1 Offers examples defined by the negotiator

\begin{tabular}{lllll}
\hline Offer number & \multicolumn{2}{l}{ Option values } & Score \\
\cline { 2 - 5 } & Price & Time of delivery & Time of payment & \\
\hline 1 & 4,700 & 50 & 7 & 0.75 \\
2 & 4,000 & 30 & 14 & 0.40 \\
3 & 3,700 & 20 & 21 & 0.20 \\
4 & 3,500 & 55 & 14 & 0.30 \\
\hline
\end{tabular}

Table 2 Offers examples defined by the negotiator

\begin{tabular}{llll}
\hline Offer number & \multicolumn{2}{l}{ Normalized matrix $N$} & \\
\cline { 2 - 4 } & Price & Time of delivery & Time of payment \\
\hline 1 & 0.81 & 0.78 & 0.67 \\
2 & 0.38 & 0.33 & 0.33 \\
3 & 0.19 & 0.11 & 0.00 \\
4 & 0.06 & 0.89 & 0.33 \\
\hline
\end{tabular}

\subsection{An Illustrative Example}

Let us consider the problem of building a scoring system for an individual negotiator according to the algorithm proposed in Sect. 3.1 and applying the alternative approach for distance function formulation proposed in Sect. 4.1. According to the algorithm the negotiation issues are defined first (step 1), which are: 1. price (USD), 2. time of delivery (days) and 3. time of payment (days). Then (step 2) the negotiators define the aspiration and reservation packages. Assuming that one is a seller in buyer-seller negotiations, he declares: $A_{a s p}=(5,000 ; 60,0)$ and $A_{\text {res }}=(3,400 ; 15 ; 21)$. As we see, the first two criteria are the benefit criteria (the higher the value, the better), while the third one is a cost criterion (the lower the value, the better). Our negotiator specifies then the weights of the negotiation issues (step 3) that are: $w_{1}=0.5, w_{2}=0.3$ and $w_{3}=0.2$. In step 4 we initiate the normalization formulas according to the formula (9) for each criterion separately. To initiate the distance formulas (step 5) we use the alternative approach proposed in the previous section. The negotiator declares then a few offer examples and assigns them the scores reflecting his preferences (the set $O$ and the vector $S^{O}$ ). The list of such offers is shown in Table 1 .

To use the above data in the optimization model, we need to find the normalized matrix first. We build it (see Table 2) by using the formula initiated in the step 4 and then we identify the PIS and NIS solutions according to the formulas (10) and (11), which simply are: $A^{+}=(1,1,1)$ and $A^{-}=(0,0,0)$.

Now, we find the separation measures $\hat{d}_{j}^{+}$and $\hat{d}_{j}^{-}$[formulas (25) and (26)] to determine the distances between PIS and NIS for each of the offers respectively, and we introduce them to the formula (22) to obtain the constraints for the model. For example, the distance formulas built for offer number 1 are as follows: 
Table 3 Detailed results of the model "optimization"

\begin{tabular}{lllllll}
\hline$\sum_{q}^{I} Y_{i=1}^{+}+\sum_{i=1}^{I} Y_{i}^{-}$ & \multicolumn{2}{l}{\begin{tabular}{l}
$l$ \\
\multicolumn{2}{l}{$(0.61,4.30,0.27)$}
\end{tabular}} & & & \\
\cline { 2 - 7 } Constraints & $\hat{d}_{i}^{+}$ & $\hat{d}_{i}^{-}$ & $\frac{\hat{d}_{i}^{-}}{\hat{d}_{i}^{-}+\hat{d}_{i}^{+}}$ & $Y_{i}^{+}$ & $Y_{i}^{-}$ & $S_{i}^{O}$ \\
\hline 1 & 0.25 & 0.68 & 0.73 & 0 & 0.015 & 0.75 \\
2 & 0.55 & 0.34 & 0.38 & 0 & 0.020 & 0.40 \\
3 & 0.85 & 0.21 & 0.20 & 0 & 0 & 0.20 \\
4 & 0.68 & 0.30 & 0.31 & 0.008 & 0 & 0.30 \\
\hline
\end{tabular}

$$
\begin{aligned}
\hat{d}_{1}^{+}= & \sum_{k=1}^{n} w_{k} \sqrt[q_{k}]{\left|1-\frac{o_{i k}-x_{k}^{\text {res }}}{x_{k}^{a s p}-x_{k}^{r e s}}\right|}=0.5 \sqrt[q_{1}]{|1-0.81|}+0.3 \sqrt[q_{2}]{|1-0.78|} \\
& +0.2 \sqrt[q_{3}]{|1-0.67|} \\
\hat{d}_{1}^{-}= & \sum_{k=1}^{n} w_{k} \sqrt[q_{k} \mid]{\mid 0-\frac{o_{i k}-x_{k}^{\text {res }}}{x_{k}^{\text {asp }}-x_{k}^{\text {res }} \mid}}=0.5 \sqrt[q_{1}]{|0-0.81|}+0.3 \sqrt[q_{2}]{|0-0.78|} \\
& +0.2 \sqrt[q_{3}]{|0-0.67|},
\end{aligned}
$$

The constraint of the model, formulated on the basis of the above formulas, is of the following form:

$$
\begin{aligned}
& \frac{0.5 \sqrt[q_{1}]{0.81}+0.3 \sqrt[q_{2}]{0.78}+0.2 \sqrt[q_{3}]{0.67}}{\left(0.5 \sqrt[q_{1}]{0.19}+0.3 \sqrt[q_{2}]{0.22}+0.2 \sqrt[q_{3}]{0.33}\right)+\left(0.5 \sqrt[q_{1}]{0.81}+0.3 \sqrt[q_{2}]{0.78}+0.2 \sqrt[q_{3}]{0.67}\right)} \\
& -Y_{1}^{+}+Y_{1}^{-}=0.75
\end{aligned}
$$

Similar constraints are formulated for all remaining offers identified by the negotiator for set $O$ (for the full model see "Appendix"). Having defined all the model constraints, we may perform the optimization phase. Since this case is relatively small, we may use the solver of Excel 2003 to find the solution of the problem, although it should be noticed, that using this tool may lead to the local optima. As a result of the optimization process, we obtain the "optimal" solution specifying the values of $q_{k}$ coefficients: $q_{1}=0.61, q_{2}=4.30$ and $q_{3}=0.27$ with the objective function at the level of 0.04. All detailed results for the remaining variables are shown in Table 3.

Now the $q_{k}$ coefficients may be used to build a scoring formula (step 6), which can be used for the evaluation any single offer from the feasible negotiation space, i.e. that falls between the feasible ranges of values defined by the aspiration and reservation levels. We obtain thus:

$$
S_{j}=\frac{0.5 \sqrt[0.61]{\widehat{x}_{1 k}}+0.3 \sqrt[4.3]{\hat{x}_{2 k}}+0.2 \sqrt[0.27]{\hat{x}_{3 k}}}{\left(0.5 \sqrt[0.61]{\left|1-\widehat{x}_{1 k}\right|}+0.3 \sqrt[4.3]{\left|1-\widehat{x}_{2 k}\right|}+0.2 \sqrt[0.27]{\left|1-\widehat{x}_{3 k}\right|}\right)+\left(0.5 \sqrt[0.61]{\hat{x}_{1 k}}+0.3 \sqrt[4.3]{\hat{x}_{2 k}}+0.2 \sqrt[0.27]{\widehat{x}_{3 k}}\right)} .
$$


Table 4 Salient options for negotiation template in exemplary business negotiation

\begin{tabular}{llll}
\hline Options & Issues & & \\
\cline { 2 - 4 } & Price (USD) & Time of delivery (days) & Time of payment (days) \\
\hline 3,400 & 14 & 7 \\
4,000 & 21 & 14 \\
4,700 & 30 & 21 \\
5,000 & & \\
\hline
\end{tabular}

Let us consider now, that in the actual negotiations the seller's counterpart has proposed a following offer: he is going to pay 4,800 USD and willing to pay in 7 days but expects the delivery within 15 next days. To score this offer we need only to normalize it. We obtain the normalized offer of the following form $(0.88,0.00,0.33)$. We introduce this values into the scoring formula (30) and find the score of the offer $S_{j}=0.53$. Thus the seller will find it as being of medium quality.

\section{TOPSIS Based Scoring Systems in Negotiation Symmetric Analysis}

The TOPSIS modified algorithm, we have described in the previous sections of the paper, allows each negotiating party to build their own scoring system for negotiating offers. Usually, each negotiator uses it individually for evaluation of both the predefined alternatives for negotiated agreement (the prenegotiation preparation) and the true offers, and counteroffers exchanged (the actual negotiation phase). However it may be also used by the third party (facilitator, mediator etc.) in the symmetric analyses of the negotiation process, mainly to find the efficient frontier and recommend to the negotiators the Pareto-optimal contracts that leave no gains on the negotiation table. It may be also supportive in finding improvements of a negotiated contract in the postnegotiation analysis. These analyses are similar to the ones that are usually conducted when the scoring is performed by means of the classic simple additive weighting model (see Raiffa et al. 2002). Yet, the TOPSIS based scoring system allows for analyzing the negotiation problems with the continuous negotiation space, i.e. when all or some of negotiation issues are described numerically by the upper and lower limits of the feasible range only and have a continuous character.

Let us consider here the case of the discrete business negotiation problem, which would allow us to discuss the problem we have already addressed in Sect. 2.2 (Problem 2). The negotiation template is similar to the one we analyzed in Sect. 4.2 and consists of three negotiation issues: price (kUSD), time of delivery (days) and time of payment (days). We will assume that the buyer considers issues of price and time of delivery as the cost criteria (he wants to minimize the value of them) and the issue of time of payment as the benefit criterion (he wants to maximize it). The global preferences of the seller are opposite. Therefore, to keep the individual negotiation problems to be a vector maximization ones we will multiply the values of cost criteria by -1 for each negotiator. We further assume that in the prenegotiation phase the negotiators have identified the sets of salient options for all the negotiation issues (Table 4). 

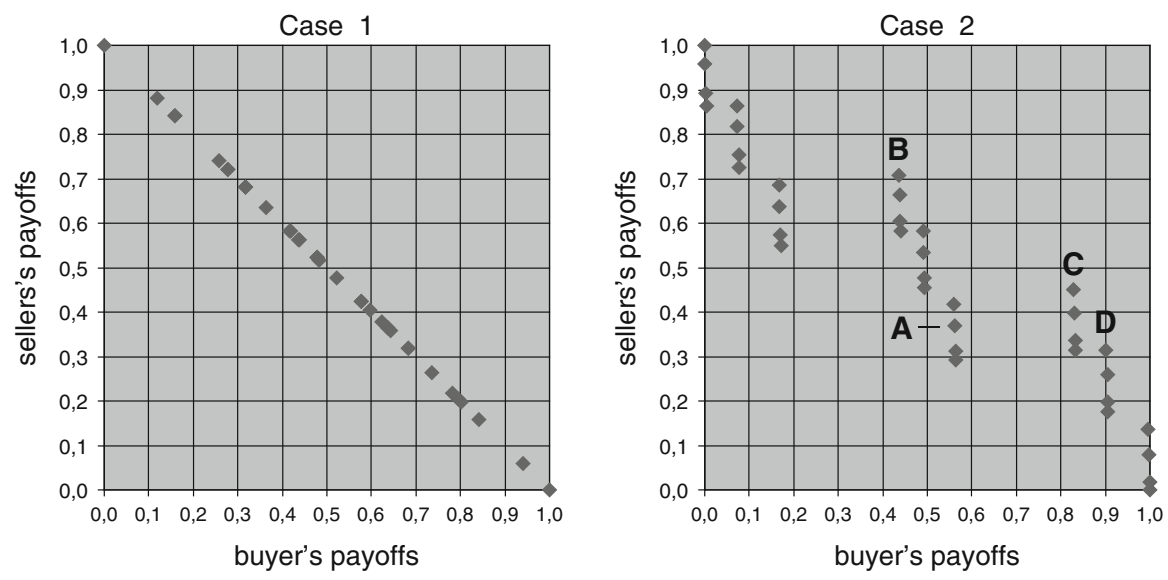

Fig. 2 Joint payoffs graphs

We will construct now the scoring systems for both the negotiators and analyse the whole negotiation problem from the perspective of the third party, who was asked to support negotiators in finding the "best" and "fair" compromise solution. Let us consider two different situations. In the first one we assume that the parties follow the standard TOPSIS algorithm to score the template with the predefined distance (see Sect. 2.1), in the second we use the alternative approach, where the distance functions are inferred from the assignments of offers specified by the parties (see Sect. 4). The differences between these two cases will be more evident if we assume that both the negotiators assigned the same weights to the issues under consideration, e.g. $w_{1}=w_{2}=(0.5,0.3,0.2)$. For both cases we will apply the same normalization formula (2). In the first case we use the distance formulas (6) and (7) with $p=1$. In the second case we use the individual distance function parameters, e.g. for buyer: $q_{k}^{\text {buyer }}=(2.0,1.0,0.5)$ and for seller: $q_{k}^{\text {seller }}=(1.2,1.0,0.8)$. We perform the TOPSIS scoring procedures and determine the scoring systems for offer negotiation from both negotiators. Now we may use the joint payoffs graphs to visualize all feasible alternatives and their consequences (scores) to both negotiators (Fig. 2).

In the case 1 the negotiation situation seems to be very peculiar. All feasible offers are located on the straight line joining two extreme points on the payoffs graph (1.0, $0.0)$ and $(0.0,1.0)$. They are the points representing the offers that are the best for one negotiator (assuring the maximum possible score for him) and simultaneously the worst for his counterpart (giving nothing to him). The other offers are represented by the points that can be determined by the linear interpolation between the extreme ones. From the third party perspective it means, that there is no potential for the joint gains in this negotiation. There are no moves possible that would increase the scores of both the negotiators simultaneously. The concession made by one party is simultaneously the improvement to the other. What is more, the value of which one concedes is equal to the gains of his counterpart. From the game theoretic point of view it is an example of two-person constant-sum game, that usually describes a strongly competitive decision problem. Consequently, the third party is not able to propose any 


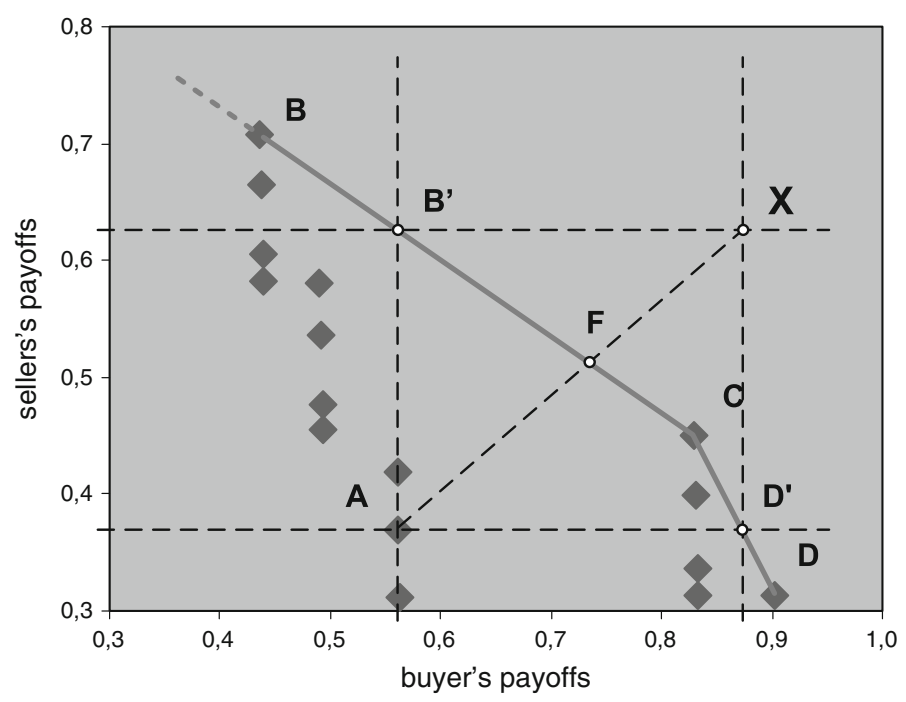

Fig. 3 The efficient frontier and the negotiation set of the game

improvement to a negotiated agreement, since there are no dominated and dominant offers in such a scoring space. Moreover, if both negotiators know the rules of the scoring mechanism, they also know the scoring systems of their counterparts. Thus, the individual preferences are mutually known and while submitting the negotiation offer each party knows both its own scoring and the counterpart's one. The situation does not change whenever other Minkowski metrics are used (i.e. the $p$ parameter is changes), however, different issue weights assigned by the parties will influence the scoring systems and change the game to the cooperative form.

In the case 2 the situation is different. The individual distance formulas applied in the negotiators' scoring systems reflect the subjective preferences of both parties. It appears now, that for some contracts the joint improvements exists and the third party may use this information to suggest the negotiators the potential direction of moves, both in the actual negotiation phase and in the post-negotiation analysis. For example, if the negotiators have decided for contract $\mathrm{A}$, the third party may indicate the contract $\mathrm{C}$ to be more profitable for both of them. The contract $\mathrm{C}$ dominates $\mathrm{A}$ and comprises the efficient frontier, which means there is no other contract that results in higher payoffs for both negotiators simultaneously. If the negotiation contracts randomization is possible (see Raiffa et al. 2002) other mechanisms may be implemented in the symmetric analysis of the negotiations to find a "fair" alternative to A. The negotiation set of the game may be built (von Neumann and Morgenstern 1944), which is a part of the efficient frontier that comprises the offers dominant to offer $\mathrm{A}$-here, the fragment of the frontier spreads on the points $\mathrm{B}^{\prime}, \mathrm{C}$ and $\mathrm{D}^{\prime}$ (Fig. 3).

Having identified the negotiation set of the game, some concepts of fair solution may be applied (see Nash 1950; Kalai and Smorodinsky 1975) to find, which of the negotiation set points should be suggested to the negotiators as the "best" improvement of their contract A. One of such a solution is based on the notion of the bliss point 
(Raiffa 1953), the coefficients of which are the maximum feasible values, the negotiators may achieve with respect to a reference point that is set in advance. In our case, the reference point is contract $A$ and the maximum feasible value for the buyer is a payoff he receives for $\mathrm{D}^{\prime}$, and for the seller-a payoff he receives for $\mathrm{B}^{\prime}$. The differences in the payoffs between $\mathrm{D}^{\prime}$ and $\mathrm{A}$ (for the buyer) and between $\mathrm{B}^{\prime}$ and $\mathrm{A}^{\prime}$ (for the seller) are called their potentials. The bliss point would be the joint maximum feasible point (out of the feasible negotiation space), namely point $X$. The intersection of the efficient frontier and the line joining $\mathrm{A}$ and $\mathrm{X}$ is considered here to be a fair solution $(\mathrm{F})$, since it assures that both negotiators receive the equal proportion of their potentials.

As we see, if the TOPSIS based scoring system is applied to supporting both negotiators, it allows for conducting the symmetric analysis by a third party. It aims to find improvements for negotiation contracts suggested in subsequent negotiation rounds and assures the negotiation compromise to be efficient. From the functional point of view the scope of the symmetric support given by the TOPSIS scoring is the same as for the analysis that can be performed when the SAW model is used.

\section{Implementing TOPSIS Modified Algorithm in Negotiation Software Support Tool}

The approach we proposed in Sects. 3 and 4 may be implemented as a supportive procedure for scoring offers in electronic negotiation system, which will allow for accomplishing its decision function. A simple electronic negotiation support tool called TOBANS 1.0 (TOPSIS based negotiation support system) has been prepared that allows for conducting bilateral multi-issue negotiations. This tool permits negotiators to define negotiation problem and template, elicits their preferences by means of the TOPSIS based procedure, and lets them to exchange messages and offers in order to find the compromise. The offers exchanged are scored according to the negotiators' individual scoring systems to help the parties make a decision whether to accept them or not. The whole sequence of the offers exchanged is depicted on the negotiation history graphs that allow for tracking the negotiation progress and analyzing the pace of concessions made by both the parties. While presenting the system interface, we will use an example similar to the ones we used in Sects. 4.2 and 5. We will introduce, however, one qualitative issue to show how the verbally defined options are scored in TOBANS. Let us consider the negotiation between a buyer and a seller, during which three following negotiation issues need to be discussed: price (USD), time of delivery (days) and warranty policy. The first two issues are of the quantitative character while the third one is described qualitatively. The feasible warranty policies are: 1 year of warranty including repairs in his own service centre (the client has to deliver the products for reparations - (1SC), 1 year of warranty and repairs at the client's office (1CO), 2 years warranty with repairs in service centre (2SC) and 2 years warranty with repairs at the client (2CO). Furthermore, we will assume that the feasible ranges for qualitative issues have also been agreed by the negotiators within the prenegotiation talks, so the price may vary from 3,000 USD to 5,000 USD and the time of delivery from 7 to 60 days. These data may be now introduced into TOBANS system as a definition of the negotiation problem. 


\begin{tabular}{|c|c|c|c|c|c|}
\hline - Megotation problem & \multicolumn{5}{|c|}{ Preference elicitation } \\
\hline $\begin{array}{l}\text { - Preferenceesicatation } \\
\text { - Offers evaluation } \\
\text { - kegotiation } \\
\text { - Logout }\end{array}$ & \multicolumn{5}{|c|}{$\begin{array}{l}\text { Step } 1 \text { - Issues' weighting and orders' building } \\
\text { - You need to declare the importance of issues by assigning the weights to each of them. Use the percentages } \\
\text { that will reflect what is the share of each issue in the whole negotiation problem. The higher the weight the } \\
\text { more important the issue is. Remember that all weights assigned must sum up to } 1 \text {. } \\
\text { - Define the preorder of options for all qualitative issues. It requires assigning the numbers reflecting the option } \\
\text { ranking. The option defined as your aspiration level is the most preferred and is the first in the ranking. The } \\
\text { option defined as your reservation level is the last one in your ranking. You have to decide about the ranks of } \\
\text { other options. }\end{array}$} \\
\hline \multirow{9}{*}{ - Logout } & Issue: & Price & Time of delivery & & Warranty conditions \\
\hline & Weights: & 0.5 & 0.3 & & 0.2 \\
\hline & Options: & (kUSD) & (days) & Rank & Description \\
\hline & Aspiration level & 5000 & 60 & 1. & 1 year, repairs in service centre \\
\hline & $\ldots$ & $\ldots$ & $\ldots$ & 3 & 1 year, repairs in client's office \\
\hline & $\ldots$ & $\ldots$ & $\ldots$ & 2 & 2 years, repairs in service centre \\
\hline & Reservation level & 3400 & 15 & 4. & 2 years, repairs in client's office \\
\hline & \multicolumn{3}{|c|}{$<-$ Redefine negotiation problem } & & Choose preference functions $\rightarrow$ \\
\hline & \multicolumn{4}{|c|}{ ๑ $2012-\mathrm{tw}$} & \\
\hline
\end{tabular}

Fig. 4 Defining negotiation space and preorder of qualitative options in TOBANS system

The user menu in TOBANS consists of both the list of pre-negotiation tasks, and the links used in the actual negotiation phase. The pre-negotiation menu reflects the subsequent steps of the TOPSIS modified algorithm and includes: (1) the definition of a negotiation problem and negotiation space, (2) the specification of aspiration and reservation levels, (3) the elicitation of negotiator's preferences, and (4) the analysis of alternatives for a negotiation agreement. The actual negotiation phase menu consists of (5) the offers and messages exchange, and (6) the visualization of the negotiation history (see the left hand side menu in Fig. 4).

TOBANS users start the work with the system with the problem definition (link 1). The system asks users for the verbal description of negotiation issues (names) and requires the type of an issue (the scale used). If the issue is defined as the ordinal or nominal one (qualitative issue), the system asks the user to specify the names of options that may be negotiated. If the issue is quantitative, the feasible range needs to be defined. Then (link 2), the user defines the aspiration and reservation values for quantitative issues. TOBANS recognizes the preference direction for all declared quantitative issues. If $x_{k}^{a s p}<x_{k}^{\text {res }}$ the issue is considered to be the cost criterion (negotiator wants to minimized it), otherwise it is considered to be the benefit criterion. For qualitative issues the aspiration and reservation options have to be declared that would indicate the first and the last option within the options' preorder. We will consider the individual support that TOBANS gives to the users from the perspective of the seller. Let us assume then that in the analyzed case he declares the following levels: $A_{\text {asp }}=[5,000 ; 60 ; 1$ year, repairs in service centre $]$ and $A_{\text {res }}=[3,400 ; 15 ; 2$ years, repairs at client's office].

After this general definition of the negotiation problem, TOBANS users enter the preference elicitation phase (link 3). Firstly, the system presents the preference direc- 


\section{Preference elicitation}

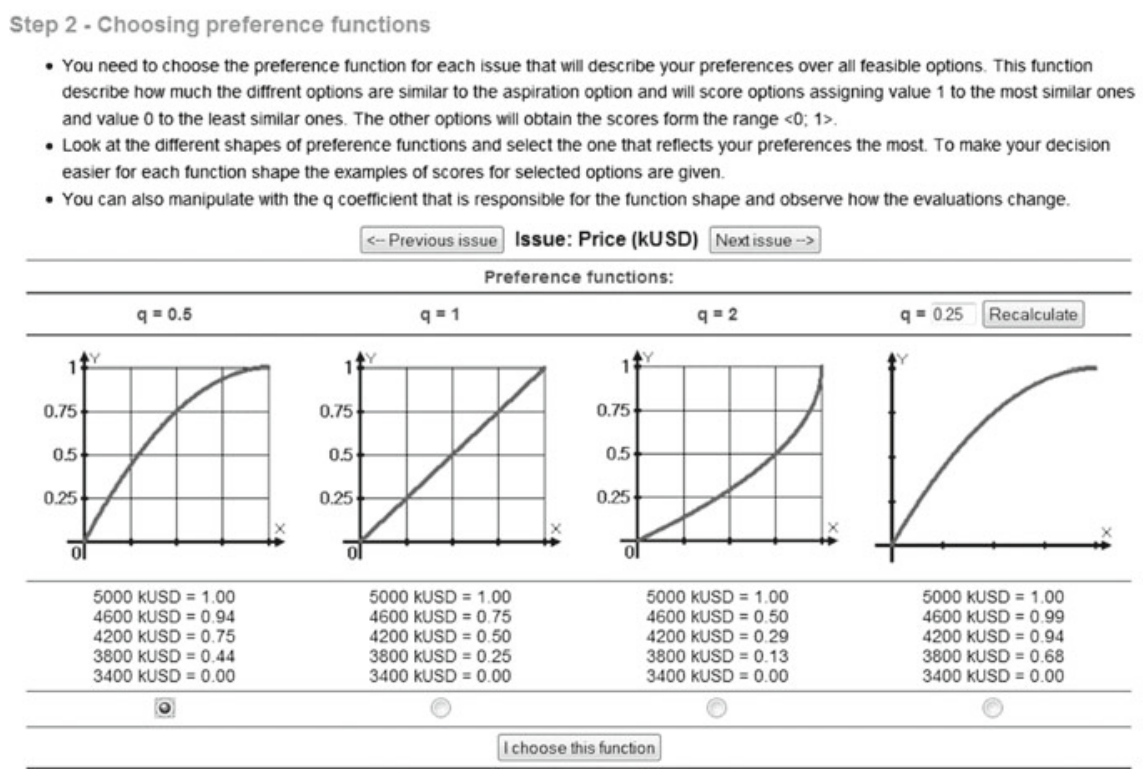

Fig. 5 Defining the form of the preference (distance) function in TOBANS

tion for quantitative issues (derived from the aspiration and reservation levels) and asks the negotiator to declare the weights for all issues under consideration. The negotiator also needs to define the preorder for the set of options within each qualitatively defined issue (see Fig. 4). As we see, the seller defined his preferences over these potential qualitative solutions defining a preorder: $1 \mathrm{SC}, 2 \mathrm{SC}, 1 \mathrm{CO}, 2 \mathrm{CO}$. He also assigned the following weight to the issues: $w=(0.5,0.3,0.2)$.

The next step of the preference elicitation involves the definition of the forms of the distance functions. TOBANS users may define these forms explicitly or by specifying the examples of offers. In the first case, three different forms of similarity functions are presented to the negotiator with the values of the similarity indices calculated for some options selected from the range between $x_{k}^{a s p}$ and $x_{k}^{r e s}$. The negotiator may select one of the predefined forms or manipulate with the root coefficient $q_{k}$ to obtain his own form of function describing his preferences in the most accurate way (see Fig. 5).

In the second situation TOBANS follows an alternative path of inferring the distance function parameters described in Sect. 4. The users are asked to define the examples of the offers (complete packages) and assign the numerical evaluation (i.e. the satisfaction) to each of them (Fig. 6). Then the system initiates the calculation engine with the data entered by the users and infers the $q_{k}$ coefficients of the distance measures. Currently TOBANS has not implemented any of the dedicated software packages for solving the goal programming problem that is built on the basis of the users assignments. A simple heuristic is implemented instead, that checks which of the possible combinations of predefined levels of $q_{k}$ coefficients results in the lowest value of the objective function. 


\section{Preference elicitation}

\section{Step 2 - Infering the forms of distance function}

- TOBANS may help you in determining q coefficients of the single-criterion distance functions. You will only need to identify a few examples of the offers, the quality (score) of which you find easy to set.

- Define the examples of the full packages, specyfying for each of them the resolution levels for all negotiation issues and the global score in a form of the percentage rate of the satisfaction this offer gives to you. Use the numers form the range $\langle 0,1\rangle$.

\begin{tabular}{|c|c|c|c|c|}
\hline No. & Price & Time of delivery & Warranty conditions & Score \\
\hline 1. & 4700 & 50 & 1 year, repairs in service centre & 0.75 \\
\hline 2. & 4000 & 30 & 2 years, repairs in service centre - & 0.4 \\
\hline 3. & 3700 & 20 & 1 year, repairs in clients office & 0.2 \\
\hline \multirow[t]{2}{*}{4.} & 3500 & 55 & 2 years, repairs in service centre - & 0.3 \\
\hline & & & & Add another example \\
\hline
\end{tabular}

\section{Calculate $q$ coefficients}

Fig. 6 Defining the offers' examples for inferring the $q$ coefficients

Having defined the user's preferences TOBANS determines the exact form of the scoring function (8) initiating all the contributing formulas with the parameters derived from the users declarations. For example, if we assume that the user has defined the problem as shown in Fig. 4, having chosen the following distance functions coefficients $q=(0.5,1.2,1.7)$, the scoring function (8) will use then the following distance formulas:

$$
\begin{aligned}
d_{j}^{+}= & 0.5 \sqrt[0.5]{\mid 1-\frac{x_{j, \text { price }}-3,400}{5,000-3,400 \mid}}+0.3 \sqrt[1.2]{\left|1-\frac{x_{j, \text { time }}-15}{60-15}\right|} \\
& +0.2 \sqrt[1.7]{\left|1-\frac{x_{j, \text { warranty }}-1}{4-1}\right|}, \\
d_{j}^{-}= & 0.5 \sqrt[0.5]{\left|0-\frac{x_{j, \text { price }}-3,400}{5,000-3,400 \mid}\right|}+0.3 \sqrt[1.2]{\left|0-\frac{x_{j, \text { time }}-15}{60-15}\right|} \\
& +0.2 \sqrt[1.7]{\left|0-\frac{x_{j, \text { warranty }}-1}{4-1}\right|} .
\end{aligned}
$$

The process of initiating the scoring formula has already been presented in details in Sect. 4.2.

The last activity provided by TOBANS in the prenegotiation phase is the evaluation of negotiation alternative compromises. The system presents to the negotiator a short list of the feasible negotiation offers, being the combination of various options for each predefined issue. The offers are scored and ranked in the descending order to present the potential concessions the negotiator may make and the corresponding trade-offs. If necessary, the negotiator may return to the previous stage of preference analysis and change the forms of distance functions. Moreover, TOBANS allows the negotiator to score any other offer built by the negotiator. The system includes this 


\section{Offers evaluation}

You have submitted for evaluation the following negotiation offer:

\begin{tabular}{ll}
\hline Price (KUSD): & 4750 \\
\cline { 1 - 1 } Time of delivery (days): & 25 \\
\cline { 1 - 2 } Warranty conditions: & 2 years, repairs in service centre \\
\hline \multicolumn{2}{l}{ Change Submit new offer }
\end{tabular}

Please find below the position of your offer in the final TOPSIS based scoring system. You may delete the offers from the list, change the existing offers or add new ones for evaluation.

\begin{tabular}{lcccc}
\hline & Price (kUSD) & Time of delivery (days) & Warranty conditions & Score \\
\hline$\square$ & 5000 & 60 & 1 year, repairs in service centre & 100 \\
\hline$\square$ & 4766 & 51 & 2 years, repairs in service centre & 93 \\
\hline$\square$ & 4756 & 53 & 2 years, repairs in client's office & 72 \\
\hline$\square$ & 4570 & 25 & 2 years, repairs in service centre & 68 \\
\hline$\square$ & 4553 & 29 & 2 years, repairs in service centre & 65 \\
\hline$\square$ & 4584 & 31 & 1 year, repairs in client's office & 57 \\
\hline$\square$ & 3875 & 59 & 2 years, repairs in client's office & 43 \\
\hline$\square$ & 3520 & 46 & 2 years, repairs in service centre & 33 \\
\hline$\square$ & 4084 & 21 & 2 years, repairs in service centre & 31 \\
\hline$\square$ & 3575 & 34 & 2 years, repairs in client's office & 8 \\
\hline$\square$ & 3400 & 15 & 2 years, repairs in client's office & 0 \\
\hline with selection: & Modify & Delete & & \\
\hline
\end{tabular}

Fig. 7 Evaluation of the new offer in scoring system determined by TOBANS

offer to the initial predefined list and shows how good the offer is in comparison to other possible solutions (see Fig. 7).

TOBANS will also accept the evaluation of the offers from outside of the scoring system, i.e. the feasible offers that consist of the options from outside the range defined by the aspiration and reservation levels. However, the options worse than $x_{k}^{r e s}$ will be treated as equal to $x_{k}^{r e s}$ and in the final evaluation TOBANS will mark the evaluated offer as being "below-bad". Similarly, the options better than $x_{k}^{a s p}$ will be treated as equal to $x_{k}^{a s p}$ but TOBANS will mark the evaluated offer as being "above-good".

The second group of TOBANS activities is related to the actual negotiation phase. Here the TOBANS functionalities are similar to the ones provided by other electronic negotiation systems, such as Inspire (Kersten and Noronha 1999) or Negoisst (Schoop et al. 2003). TOBANS provides its users with a simple communication tool for asynchronous exchange of offers and messages. The user may build the offer using the predefined issues, and write a text message including the argumentation line in a message box below (Fig. 8).

Due to the specific form of the scoring formula imposed by the TOPSIS algorithm TOBANS is able to score the offer constructed the negotiator only if the whole package is built. This may be considered as a drawback, especially if compared with the support given by the systems based on SAW, where the partial scores may be calculated for the 


\section{Negotiation - send an offer}

Specify the offer you wish to send to your counterpart:

\begin{tabular}{|c|c|c|}
\hline & Offer & \\
\hline Price (kUSD): & & 4570 \\
\hline Time of delivery (days): & & 25 \\
\hline Warranty conditions: & 2 years & service centre - \\
\hline
\end{tabular}

\section{Calculate the offer's score}

Write a message to your counterpart

Dear atefe,

I have thought of the last offer you sent me and consulted it with my sales executive. It appears that according to our logistic requirements we are not able to sent you the shipping sooner than after 25 days. However we may compensate this time with a little bit lower price. How do you find this solution?

Fig. 8 Offers and messages preparation in TOBANS

incomplete offers. So, the negotiator may track the score of the offer after specifying each subsequent option of the offer, knowing the value of each single resolution level.

TOBANS also allows negotiators to track the negotiation progress. It draws the negotiation history graph showing the concession made in the subsequent rounds of negotiation by both the negotiators. The offers depicted on the graph are scored according to the negotiator's individual preferences, no information on the counterpart preferences is revealed then to the negotiator. The shapes of the concession paths of both the parties show the negotiation dynamics. The user may easily know what are the scales of concession on each negotiation stage and whether the reverse concessions were made. Below the history graph TOBANS specifies the details of each offer (Fig. 9).

If the parties agree on one of the offers sent to be a negotiation final contract (compromise) the negotiation ends. Currently there are no post-negotiation procedures implemented in TOBANS system, but it is possible to apply any of the methods of improving the negotiation compromise, that were mentioned in Sect. 5.

\section{Conclusions}

In this paper we have presented a novel approach to building the scoring system for negotiating offers by means of the modified TOPSIS method. The modification we suggested focused on three aspects of the classic algorithm: a requirement of the discrete form of the decision (negotiation) problem, the classic Manhattan or Eucledean distance formulas usually used in the TOPSIS analysis and the metric variables required by the method.

In our modified approach we use the notion of aspiration and reservation levels (instead of defining the full set of feasible alternatives) and change the normalization formula, which allowed for building a scoring function that may be used for continuous negotiation problem as well as for the discrete one. The further modification in measuring distances, in particular the application of the notion of rooting the classic 


\section{Negotiation history}

Below you find the negotiation history graph. The offers made by you and your conterpart are depicted on the graph and joined to visualize the concession paths:

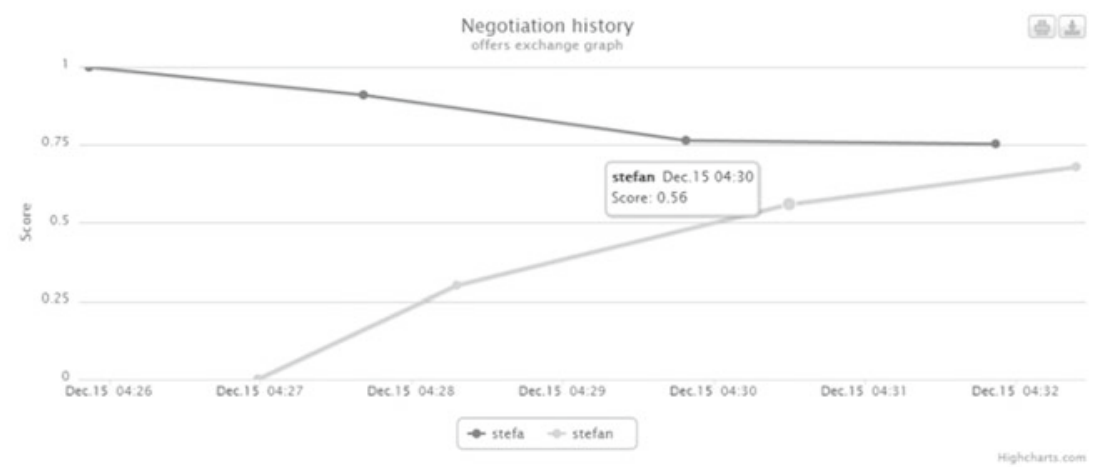

The list of offers exchanged in the negotiation process:

\begin{tabular}{|c|c|c|c|c|c|c|c|}
\hline Date & Sender & & & Score & Message & & Action \\
\hline \multirow{3}{*}{$\begin{array}{l}\text { Dec 15, } \\
04: 33\end{array}$} & \multirow{3}{*}{$\begin{array}{l}\text { stefan } \\
\text { (counterpart) }\end{array}$} & Price (kUSD) & 4700 & \multirow{3}{*}{68} & \multirow{3}{*}{$\begin{array}{l}\text { Stefa, } \\
\text { I am sorry I cannot } \\
\text { accept your last } \\
\text { offer, but think of } \\
\text { this one. }\end{array}$} & A & \multirow{3}{*}{ accept } \\
\hline & & $\begin{array}{l}\text { Time of delivery } \\
\text { (days) }\end{array}$ & 50 & & & $\equiv$ & \\
\hline & & $\begin{array}{l}\text { Warranty } \\
\text { conditions }\end{array}$ & $\begin{array}{l}1 \text { year, repairs in } \\
\text { clients office }\end{array}$ & & & 4 & \\
\hline
\end{tabular}

Fig. 9 Negotiation history

Minkowski formula with various $q_{k}$ coefficients (derived from Pawelek's 2008 earlier theoretical works) allowed for fitting the distance function to the true preference function of the negotiator mostly. In our approach the qualitative issues are also taken into consideration, however, the simplest possible solution has been proposed to measure the distances between the ordinal variables, i.e. the Kaufman and Rousseeuw (1990) measure. This measure is criticized for using the subtraction operation, which is meaningless for ordinal values. We have assumed, however, that the ordinal numbers represent the categories of equal differences in quality, therefore using the formula (18) in our model becomes legitimate. We also wanted to show that our new approach may be easily implemented into software tools to support a pre-negotiation phase. The negotiators may quickly follow three simple steps of the preference analysis and obtain the scoring system that permits them to evaluate any feasible offer that may appear later on the negotiation table during the actual negotiation process. If they are not skilled in decision making theory, they may also use an alternative path in defining their preferences and, instead of setting the unintuitive distance function parameters, build the examples of offers and evaluations that the system will use to calculate all the parameters required by the scoring algorithm. The software tool we built prepares a predefined list of offers that may stand for the reference point for the offers built by the negotiator himself. It allows for identifying the alternative offers that may be proposed to the counterpart and finding the trade-offs between different packages. Simple communication mechanism was also applied to allow for exchanging offers and mes- 
sages between the parties. TOBANS uses the information about offers exchanged to visualize the negotiation history in a graphical form.

It should be noticed, however, that the approach we propose is in fact a compensation model and similarly to the simple additive weighting and AHP may be only used for those negotiators who accept the notion of preference compensation between the issues. One advantage of the proposed algorithm over SAW and AHP should be also emphasized. By using the supportive mechanism, proposed in Sect. 4, we take from the negotiator the burden of tiresome and time consuming evaluation of all possible salient options. Instead of assigning the scores to options and issues (as it is necessary in SAW) or make dozens of pair-wise comparisons (in AHP), negotiators simply specify the examples of the offers (complete packages) that they find easy to evaluate and assign the numerical score to them (e.g. a satisfaction level). Basing on these evaluations the system finds the negotiator's preference (distance) functions by solving the goal programming problem described in details in Sect. 4.

The future work on the method will focus on analyzing the possibilities of a different representation of the "below-bad" and "above-good" alternatives. The attempts for scoring the value surpluses over the $x_{k}^{a s p}$ and the shortages to the $x_{k}^{r e s}$ will be undertaken, which would require to define the negotiators' preferences for these unfeasible values, but would allow for scoring such an alternative in a more accurate way. The research on the use and usefulness of TOBANS system would also be done in a form of the negotiation simulation involving the university students.

Acknowledgments This research was partially supported by the grant of the Polish Ministry of Science and Higher Education (N N111 234936).

Open Access This article is distributed under the terms of the Creative Commons Attribution License which permits any use, distribution, and reproduction in any medium, provided the original author(s) and the source are credited.

\section{Appendix: The Optimization Model}

$$
\left(Y_{1}^{+}+Y_{2}^{+}+Y_{3}^{+}+Y_{4}^{+}\right)+\left(Y_{1}^{-}+Y_{2}^{-}+Y_{3}^{-}+Y_{4}^{-}\right) \rightarrow \min
$$

subject to

$$
\begin{aligned}
& \frac{0.5 \sqrt[q_{1}]{0.81}+0.3 \sqrt[q_{2}]{0.78}+0.2 \sqrt[q_{3}]{0.67}}{\left(0.5 \sqrt[q_{1}]{0.19}+0.3 \sqrt[q_{2}]{0.22}+0.2 \sqrt[q_{3}]{0.33}\right)+\left(0.5 \sqrt[q_{1}]{0.81}+0.3 \sqrt[q_{2}]{0.78}+0.2 \sqrt[q_{3}]{0.67}\right)} \\
& -Y_{1}^{+}+Y_{1}^{-}=0.75 \\
& 0.5 \sqrt[q_{1}]{0.38}+0.3 \sqrt[q_{2}]{0.33}+0.2 \sqrt[q_{3}]{0.33} \\
& -Y_{2}^{+}+Y_{2}^{-}=0.4
\end{aligned}
$$




$$
\begin{gathered}
\frac{0.5 \sqrt[q_{1}]{0.19}+0.3 \sqrt[q_{2}]{0.11}+0.2 \sqrt[q_{3}]{0.00}}{\left(0.5 \sqrt[q_{1}]{0.81}+0.3 \sqrt[q_{2}]{0.89}+0.2 \sqrt[q_{3}]{1}\right)+\left(0.5 \sqrt[q_{1}]{0.19}+0.3 \sqrt[q_{2}]{0.11}+0.2 \sqrt[q_{3}]{0.00}\right)} \\
-Y_{3}^{+}+Y_{3}^{-}=0.2 \\
0.5 \sqrt[q_{1}]{0.06}+0.3 \sqrt[q_{2}]{0.89}+0.2 \sqrt[q_{3}]{0.33} \\
-Y_{4}^{+}+Y_{4}^{-}=0.3 \\
q_{1}, q_{2}, q_{3}, q_{4} \geq 0 \\
Y_{1}^{+}, Y_{2}^{+}, Y_{3}^{+}, Y_{4}^{+}, Y_{1}^{-}, Y_{2}^{-}, Y_{3}^{-}, Y_{4}^{-} \geq 0
\end{gathered}
$$

\section{References}

Bellucci E, Zeleznikow J (2006) Developing negotiation decision support systems that support mediators: a case study of the Family_Winner system. J Artif Intell Law 13(2):233-271

Chamodrakas I, Alexopoulou N, Martakos D (2009) Customer evaluation for order acceptance using a novel class of fuzzy methods based on TOPSIS. Expert Syst Appl 36(4):7409-7415

Chen CT (2000) Extension of the TOPSIS for group decision-making under fuzzy environment. Fuzzy Set Syst 114:1-9

Cox TF, Cox MAA (2001) Multidimentional scaling, 2nd edn. Chapman \& Hall/CRC, Boca Raton

Gordon AD (1999) Classification, 2nd edn. Chapman \& Hall/CRC, Boca Raton

Gower JC (1971) A general coefficient of similarity and some of its properties. Biometrics 27:857-874

Hellwig Z (1968) Procedure of evaluating high level manpower data and typology of countries by means of the taxonomic method. Prz Stat (Stat Rev) 15(4):308-327

Hordijk L (1991) Use of the RAINS model in acid rain negotiation in Europe. Environ Sci Technol 25(4):596-603

Hwang CL, Yoon K (1981) Multiple attribute decision making: methods and applications. Springer, New York

Jahanshahloo GR, Lotfi FH, Izadikhah M (2006) Extension of the TOPSIS method for decision-making problems with fuzzy data. Appl Math Comput 181:1544-1551

Jones DF, Mardle SJ (2004) A distance-metric methodology for the derivation of weights from a pairwise comparison matrix. J Oper Res Soc 55:869-875

Kalai E, Smorodinsky M (1975) Other solutions to Nash's bargaining problem. Econometrica 43(3):513518

Kaufman L, Rousseeuw PJ (1990) Finding groups in data: an introduction in cluster analysis. Wiley, New York

Keeney RL, Raiffa H (1976) Decisions with multiple objectives. Wiley, New York

Kersten GE, Lai H (2007) Negotiation support and E-negotiation systems. Group Decis Negot 16(6):553586

Kersten GE, Noronha SJ (1999) WWW-based negotiation support: design, implementation and use. Decis Support Syst 25(2):135-154

Krohling RA, Campanharo VC (2011) Fuzzy TOPSIS for group decision making: a case study for accidents with oil spill in the sea. Expert Syst Appl 38(4):4190-4197

Larichev O, Moshkovich H (1997) Verbal decision analysis for unstructured problems. Kluwer, Boston

Milani AS, Shanian A, El-Lahham C (2008) A decision-based approach for measuring human behavioral resistance to organizational change in strategic planning. Math Comput Model 48(11-12):1765-1774

Milani AS, Shanian A, Madoliat R (2005) The effect of normalization norms in multiple attribute decision making models: a case study in gear material selection. Struct Multidiscip Optim 29(4):312-318

Mousseau V (1995) Eliciting information concerning the relative importance of criteria. In: Pardalos P, Siskos Y, Zopounidis C (eds) Advances in multicriteria analysis, nonconvex optimization and its applications. Kluwer, Dordrecht, pp 17-43 
Mousseau V, Slowinski R (1998) Inferring an ELECTRE TRI model from assignment examples. J Glob Optim 12(2):157-174

Mustajoki J, Hamalainen RP (2000) Web-HIPRE: global decision support by value tree and AHP analysis. INFOR 38(3):208-220

Nash J (1950) The bargaining problem. Econometrica 18:155-162

Paradis N, Gettinger J, Lai H, Surboeck M, Wachowicz T (2010) E-negotiations via Inspire 2.0: the system, users, management and projects. In: de Vreede GJ (ed) Group decision and negotiations 2010. Proceedings. The Center for Collaboration Science, University of Nebraska at Omaha, pp 155-159

Pawełek B (2008) Analyzing the sensitivity of Jeffreys-Matusit and Canberra measures for small changes of variables' values (text in Polish). Krak Univ Econ Res Pap 797:143-159

Raiffa H (1953) Arbitration schemes for generalized two-person games. In: Kuhn HW, Tucker AW (eds) Contributions to the theory of games, vol II. Princeton University Press, Princeton, pp 361-388

Raiffa H (1982) The art and science of negotiation. Harvard University Press, Cambridge

Raiffa H, Richardson J, Metcalfe D (2002) Negotiation analysis. The science and art of collaborative decision making. The Balknap Press of Harvard University Press, Cambridge, MA

Schoop M, Jertila A, List T (2003) Negoisst: a negotiation support system for electronic business-to business negotiations in ecommerce. Data Knowl Eng 47:371-401

Sebenius JK (1992) Negotiation analysis: a characterization and review. Manag Sci 38(1):18-38

Shih HS, Shyur HJ, Lee ES (2007) An extension of TOPSIS for group decision making. Math Comput Model 45:801-813

Simons T, Tripp TM (2003) The negotiation checklist. In: Lewiski RJ, Saunders DM, Minton JW, Barry BNegotiation. Reading, excersises and cases. 4th edn. McGraw-Hill/Irwin, New York

Thiessen EM, Shakun MF (2009) First nation negotiations in Canada: action research using SmartSettle. In: Kilgour DM, Wang Q (eds) Proceedings of GDN 2009: An International Conference on Group Decision and Negotiation, Wilfried Laurier University, Toronto

Thiessen EM, Soberg A (2003) Smartsettle described with the montreal taxonomy. Group Decis Negot 12(2):165-170

Von Neumann J, Morgenstern O (1944) Theory of games and economic behavior. Princeton University Press, Princeton

Wachowicz T, Kersten GE (2009) Decisions and manners of electronic negotiation system users. In: Kłosiński KA, Biela A (eds) Proceedings of an international scientific conference "A Man And His Decisions". John Paul II Catholic University of Lublin Press, Lublin, pp 63-74

Wachowicz (2010) Decision support in software supported negotiations. J Bus Econ Manag 11(4):576-597

Wachowicz T (2011) Application of TOPSIS methodology to the scoring of negotiation issues measured on the ordinal scale. In: Trzaskalik T, Wachowicz T (eds) Multiple criteria decision making'10/11. Publisher of The University of Economics in Katowice, Katowice pp 238-258

Zartman WI (1989) Prenegotiation: phases and functions. Int J 44(2):237-253

Zavadskas EK, Vilutiene T, Turskis Z, Tamosaitiene J (2010) Contractor selection for construction works by applying Saw-G and TOPSIS grey techniques. J Bus Econ Manage 11(1):34-55 